Article

\title{
Artemisinin DNA Base Interaction Studies in Presence of Fe(II): LC/TOF MS Separation of Reaction Products
}

\author{
Kogila Oke and Amos Mugweru*
}

check for updates

Citation: Oke, K.; Mugweru, A.

Artemisinin DNA Base Interaction Studies in Presence of Fe(II): LC/TOF MS Separation of Reaction Products. Separations 2021, 8, 161. https:// doi.org/10.3390/separations8090161

Academic Editor:

Wojciech Piekoszewski

Received: 19 August 2021

Accepted: 14 September 2021

Published: 18 September 2021

Publisher's Note: MDPI stays neutral with regard to jurisdictional claims in published maps and institutional affiliations.

Copyright: (c) 2021 by the authors. Licensee MDPI, Basel, Switzerland. This article is an open access article distributed under the terms and conditions of the Creative Commons Attribution (CC BY) license (https:/ / creativecommons.org/licenses/by/ $4.0 /)$.
Department of Chemistry and Biochemistry, Rowan University, Glassboro, NJ 08028, USA; vijaya86@rowan.edu * Correspondence: mugweru@rowan.edu; Tel.: +1-856-2565454; Fax: +1-856-256-4478

\begin{abstract}
Artemisinin (ART) is a sesquiterpene lactone and a popular malaria drug with potential anticancer properties. In this work, LC/TOF/MS, was used to investigate the reaction of ART with DNA bases. ART-deoxyadenosine and ART-deoxycytidine interactions, were studied in the presence of iron II ions. ART-deoxyadenosine and ART-deoxycytidine reaction mixtures gave chromatographic signatures that remained fairly unchanged at room temperature but grew after incubation at $37^{\circ} \mathrm{C}$. The change in temperature from room temperature to $37^{\circ} \mathrm{C}$ was the main driver of adduct formation in these reactions. ART was found to react with $\mathrm{Fe}$ (II) ions as observed from several new chromatographic peaks. ART-deoxyadenosine as well as ART-deoxycytidine in the presence of $\mathrm{Fe}$ (II) ions resulted in formation of new chromatographic signatures of adducts consisting of DNA bases and ART. It was clear that addition of iron (II) to DNA base-ART mixtures gave rise to new reaction products mediated by a different reaction mechanism. Studies of ART reactions with DNA in vitro is key in elucidating elusive mechanism of this drug.
\end{abstract}

Keywords: artemisinin; DNA bases; mass spectrometry; liquid chromatography

\section{Introduction}

Artemisinin (ART) is a sesquiterpene lactone consisting of an internal peroxide bridge also known as a 1,2,4-trioxane ring system [1]. ART is effective against malaria, a disease caused by the Plasmodium falciparum parasite [2]. Due to its low solubility and short half-life, other semi-synthetic derivatives have been developed [3]. Dihydro-artemisinin, one of the semi-synthetic form of ART, was derived from the primary active metabolite of ART [4]. Other first generation semi-synthetic forms of ART are arteether and artemether (lipid soluble), and artesunate (water soluble) [5].

Several studies and case reports show ART exhibiting anticancer properties against cancer cells [6,7] as well as providing enhanced synergistic activity with other anti-cancer agents [8]. The mechanism of action of ART is not well understood. However, the endoperoxide bridge of ART is thought to play a key role in the overall mechanism of action [9]. Interaction of the endo-peroxide of ART with heme in proteins is speculated to form free radicals causing cell injury and apoptosis in cells [10]. The formation of carbon centered free radicals when ART interacts with heme proteins is well known [11]. However, some research indicates that ART and its derivatives go through Fenton-like reactions to kill cancer cells $[12,13]$. ART has been reported to exhibit antileishmanial activity in particular against visceral leishmaniasis [14]. New reports indicate that this drug can be used as an anti-mycobacterial [15]. Despite ART's potential uses and decades of research, knowledge gaps concerning its mechanism and its specific targets remain glaring. For example, in a new pharmacophoric study on the role of the peroxide bond in dioxanes against Leishmania parasites no role was found for the peroxide bridge [16]. In fact, tetrahydropyran, an epoxide, was found to induce a higher increase in intracellular reactive oxygen species (ROS) levels than its endoperoxide counterpart. This implied that generation of free radicals by cleaving the $\mathrm{O}-\mathrm{O}$ bond is not the main mechanism of action in these peroxides. Presence of free iron also did not affect free radical generation [16] This is in contrast to 
multiple other studies done previously that indicated presence of Fe(II) ions, mainly from be decomposition of heme, are paramount in artemisinin's anti-Leishmania efficacy [17].

The anticancer effects of ART and its derivatives are due to the latter's ability to induce apoptosis through cellular processes including DNA damage. The iron-mediated cleavage of the endoperoxide bridge in ART could trigger the formation of the carbon centered radicals that can induce ferroptosis [18]. In general, Fe(II) in the presence of ART can trigger generation of free radicals through a Fenton-type reaction. Studies on drug and DNA interactions are important in chemotherapeutics [19]. Research into such interaction can enhance understanding of the mechanisms involved by unravelling structural changes undergone by the drug. Products of the reaction can also help tailor new therapies. A rapid separation method to help unravel the reaction products as well as help qualitatively identify the reaction products is key to the search for the reaction mechanisms.

The aim of the current work is to develop new chromatographic methods and use them to investigate the reactions of ART with DNA bases, and to establish the role of Fe(II). LC/TOF MS was used to establish the reaction products. Reaction of ART with any DNA base is key in unravelling part of the mechanism involved in the drug's anticancer activity. For the first time, the LC/TOF MS technique was used to clearly show that ART's reaction with DNA bases followed a different mechanism from that which occurs in the presence of $\mathrm{Fe}(\mathrm{II})$. The role of temperature in the activity of the drug towards the DNA bases was also established.

\section{Materials and Methods}

\subsection{Chemicals and Reagents}

ART was purchased from Tokyo Chemical Company (TCI). DNA base (2-deoxyadenosine) was purchased from sigma. DNA base (2-deoxycytidine) and Iron (II) Chloride were purchased from Alfa Aesar. Methanol, acetonitrile, ammonium acetate and water, all LC-MS grade, were purchased from VWR. Solutions of ART and its derivatives containing $20 \mathrm{mM}$ Ammonium acetate: Methanol, 15:85 were prepared prior to each experiment. All other chemicals were LC-MS grade.

\subsection{Chromatographic Procedure}

Standards of ART and DNA bases were analyzed using TOF/LC-MS. Separation of the reaction products of ART-deoxyadenosine and ART-deoxycytidine were carried out using Agilent Technologies, ZORBAX Extended C-18 column $(2.1 \times 50 \mathrm{~mm})$ with $1.8 \mu \mathrm{m}$ diameter particles. An autosampler was used to inject the sample, and the temperature was set to $25{ }^{\circ} \mathrm{C}$. The mobile phase consisted of Methanol and water 70:30, respectively. The LC-MS analysis was carried out using Agilent 6230 series LC-MS TOF unit. The chromatographic run was performed under isocratic conditions at a flow rate of $0.300 \mathrm{~mL} / \mathrm{min}$. Every end of the run was followed by a post run step that included flushing the column with mobile phase for $5 \mathrm{~min}$. The column temperature was set at $25^{\circ} \mathrm{C}$.

\subsection{Mass Spectrometer Procedure}

Mass spectrometry detection for the LC/MS was with a TOF 6230 series set to Dual AJS ESI positive ion mode. The settings of the mass spectrometer were as follows: scan mode (standard), range (200-3000) $\mathrm{m} / z$, threshold (200), nebulizer gas (40.0 psi), and dry gas $(8.0 \mathrm{~L} / \mathrm{min})$, dry temperature $\left(325^{\circ} \mathrm{C}\right)$. The compound stability and trap drive level were set to $100 \%$. The MS/MS fragmentation amp was set to $175 \mathrm{~V}$ and the skimmer cone at $65 \mathrm{~V}$.

\subsection{Sample Preparation}

\section{ART-DNA Reactions}

Solid mixtures of ART and 2-deoxyadenosine were placed in a $5 \mathrm{~mL}$ volumetric flask. In another $5 \mathrm{~mL}$ volumetric flask, ART and 2-deoxycytidine were added. A buffer solution containing 15\% ammonium acetate $(20.0 \mathrm{mM})$ and $85 \%$ methanol was added to the 
two volumetric flasks containing the solid mixtures. The final concentration of ART was $1.4 \times 10^{-2} \mathrm{M}$ while that of 2 -deoxyadenosine was $1.6 \times 10^{-2} \mathrm{M}$. The final concentration of 2-deoxycytidine was $1.8 \times 10^{-2} \mathrm{M}$. Two more solutions were made following the same procedure, but with $2 \times 10^{-3} \mathrm{M} \mathrm{Fe}^{2+}$. Equal mixtures of ART and 2-deoxyadenosine were placed in a $5 \mathrm{~mL}$ volumetric flask, and $3 \mathrm{~mL}$ of Iron II chloride solution was added to the solid mixture of ART and 2-deoxyadenosine. A buffer solution was then used to make up the $5 \mathrm{~mL}$ volume mark. The concentrations of ART and 2-deoxyadenosine were $1.4 \times 10^{-2} \mathrm{M}$ and $1.6 \times 10^{-2} \mathrm{M}$, respectively. The final solution contained $1.4 \times 10^{-2} \mathrm{M}$ ART, $1.8 \times 10^{-2} \mathrm{M}$ 2-Deoxycytidine and $2 \times 10^{-3} \mathrm{M} \mathrm{Fe}^{2+}$. For analysis, $1 \mathrm{~mL}$ of the sample mixture was drawn, filtered and transferred into individual vials. Comparisons were made between solution mixtures left at room temperature versus those incubated at $37^{\circ} \mathrm{C}$. Some sample mixtures were incubated at $37^{\circ} \mathrm{C}$ for different lengths of times before analysis.

\subsection{Optimization of the Reaction Conditions}

The concentration of standards and the chromatographic procedures were adjusted and optimized for the optimal reaction and elution of the reaction products. Initially, the ART, 2-deoxyadenosine and 2-deoxycytidine standards were analyzed individually. Various ratios of solvents were investigated in order to optimize solubility of both the ART and DNA bases as well as to effectively separate samples. The ratio of the solvents for the sample mixture preparation, $20 \mathrm{mM}$ Ammonium acetate: methanol, was adjusted to 15:85 to facilitate the solubility of the DNA base with ART. Methanol and water were used as the mobile phases for the LC-MS method; the water contained $0.1 \%$ formic acid. The ratio was adjusted to 70:30 for proper elution of the standard and reaction products. A column with the dimensions $2.1 \times 50 \mathrm{~mm}$, with $1.8 \mu \mathrm{m}$ was used for faster and more precise separation of the reaction products. In this experiment, the incubation temperature was set to $37^{\circ} \mathrm{C}$ and the column temperature was maintained at $25^{\circ} \mathrm{C}$. After optimization of the reaction conditions, each analysis were carried out three times.

\section{Results}

\subsection{ART-Deoxyadenosine}

Figure 1 shows the chemical structure of ART and its derivatives. Reaction of ART with deoxyadenosine was monitored by obtaining chromatograms of mixtures at room temperature and at $37^{\circ} \mathrm{C}$. Figure 2 shows chromatograms of the sample mixtures, first analyzed immediately after mixing and then analyzed again each day for four days. On the first day, only two chromatogram peaks corresponding to the two reactants were obtained, at or around retention times 0.4 and $1.3 \mathrm{~min}$. On the third day of incubation at $37{ }^{\circ} \mathrm{C}$ new chromatographic peaks at retention times, $0.7,0.8,0.9,1.1$ and 1.2 min were visible. Although the intensities of these peaks were very small, they signify formation of new molecules between ART and deoxyadenosine. These new chromatographic reaction product peaks grew with time of incubation, while the parent reactant peaks reduced. The initial reactant signature peaks decreased by about $17 \pm 2 \%$ to $30 \pm 4 \%$, while the new product peaks grew by about $41 \pm 4 \%$ to $100 \pm 5 \%$ during the time of incubation. Further analysis of these reaction products was carried out using mass spectra. Mass spectra corresponding to Figure 2 are shown in Figure S1 and indicate deoxyadenosine molecular ion $[\mathrm{M}+\mathrm{H}]^{+}$at $m / z$ 252. Other ions include $[\mathrm{M}+\mathrm{Na}]^{+},[\mathrm{M}+\mathrm{K}]^{+}$and $[2 \mathrm{M}+\mathrm{Na}]^{+}$, corresponding to $m / z$ of 274, 290 and 525, respectively. On the other hand ART, with a molecular weight of 282, showed molecular ions of $[\mathrm{M}+\mathrm{H}]^{+}$at $m / z 283$, in addition to other ions such as $[\mathrm{M}+\mathrm{Na}]^{+}$, $[\mathrm{M}+\mathrm{K}]^{+},[2 \mathrm{M}+\mathrm{Na}]^{+}$, corresponding to $m / z$ of 305,321 and 587 , respectively. 


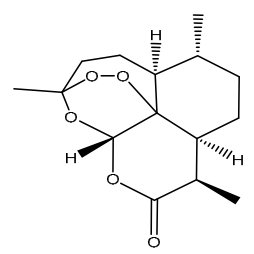

Artemisinin

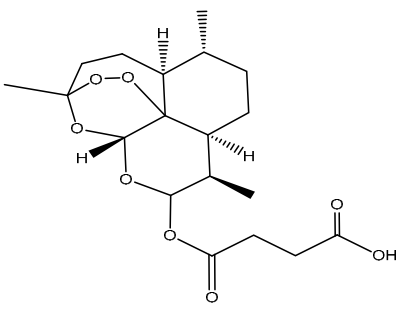

Artesunate

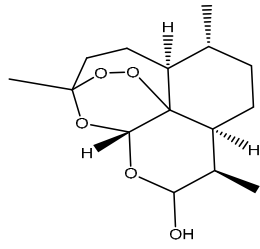

Dihydroartemisinin<smiles>CO[C@H]1O[C@H]2OC3(C)CC[C@@H](C)[C@]2(OO3)[C@@H](C)[C@@H]1C</smiles>

Artemether

Figure 1. Chemical structure of artemisinin and its derivatives.

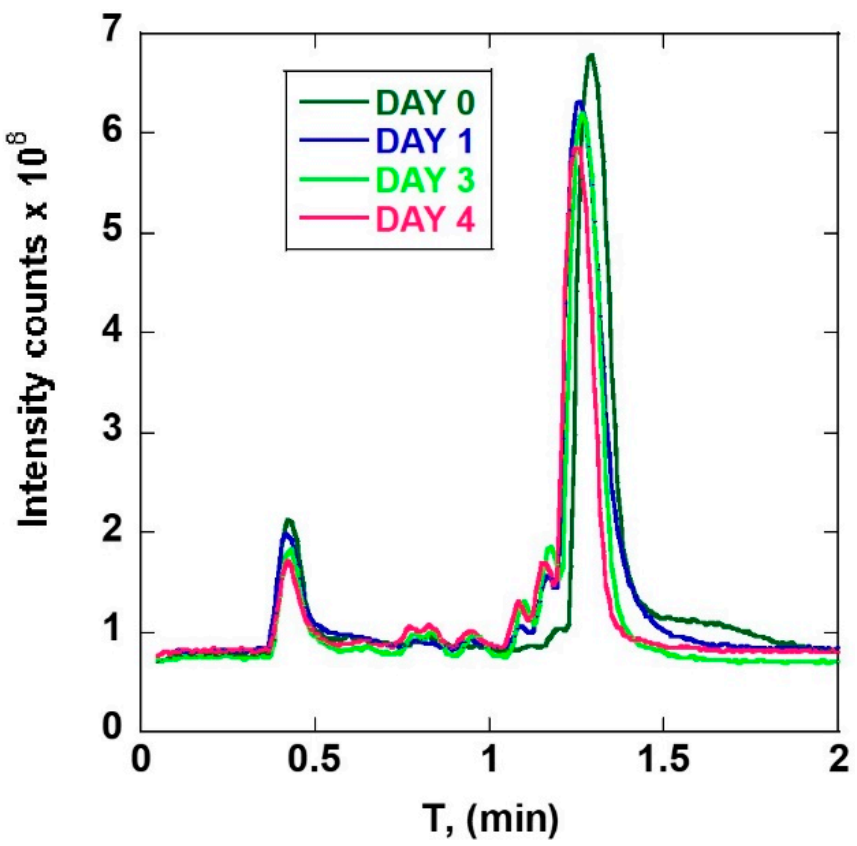

Figure 2. TIC chromatograms of the ART-deoxyadenosine reaction mixture obtained at room temperature (day zero) and at $37^{\circ} \mathrm{C}$ incubation.

Removal of water from $m / z 283$ could result in $m / z$ 265. Removal of CO from 265 could give $m / z$ 237. Removal of $\mathrm{C}_{2} \mathrm{H}_{4}$ from 237 could yield $m / z 209$, which was also the mechanism of transition from $m / z 219$ to $m / z 191$. Dehydration of $m / z 237$ could also form $m / z$ 219. These individual fragmented masses were observed in the mass spectra elsewhere [20]. Alkylation reaction most likely occurred in the ART-deoxyadenosine mixture. In principle, alkylation of 2'-deoxyadenosine can occur at nitrogen atoms N1, N6, N7, and N9. Alkylation at multiple location in deoxyadenosine may be one of the key reasons we encountered different chromatographic peaks, however at the same time these peaks showed some similar masses in the mass spectra. The new product chromatographic peaks appearing between 0.7 and 1.2 min are shown on Table 1. 
Table 1. Retention time and fragmentation patterns of Deoxyadenosine reacted with artemisinin.

\begin{tabular}{ll}
\hline Retention Time & Main Fragments $(\mathrm{m} / \mathrm{z})$ \\
\hline 0.7 & $251,337,353,399$ \\
\hline 0.8 & $237,251,307,399$ \\
\hline 0.9 & $251,307,337,353$ \\
\hline 1.1 & $251,283,305,337,353$ and 587 \\
\hline 1.2 & $209,237,251,265,337$ and 353 \\
\hline
\end{tabular}

Although these are pure molecules as observed from single chromatographic peaks, the mass spectra showed a combination of deoxyadenosine and ART, meaning that they were adducts. A possible mechanism of deoxyadenosine (dA) alkylation on the N1, N6, N7, and N9 positions by ART under temperature control is shown in Figure 3. This alkylation mechanism of deoxyadenosine was previously reported as a possibility in [21].

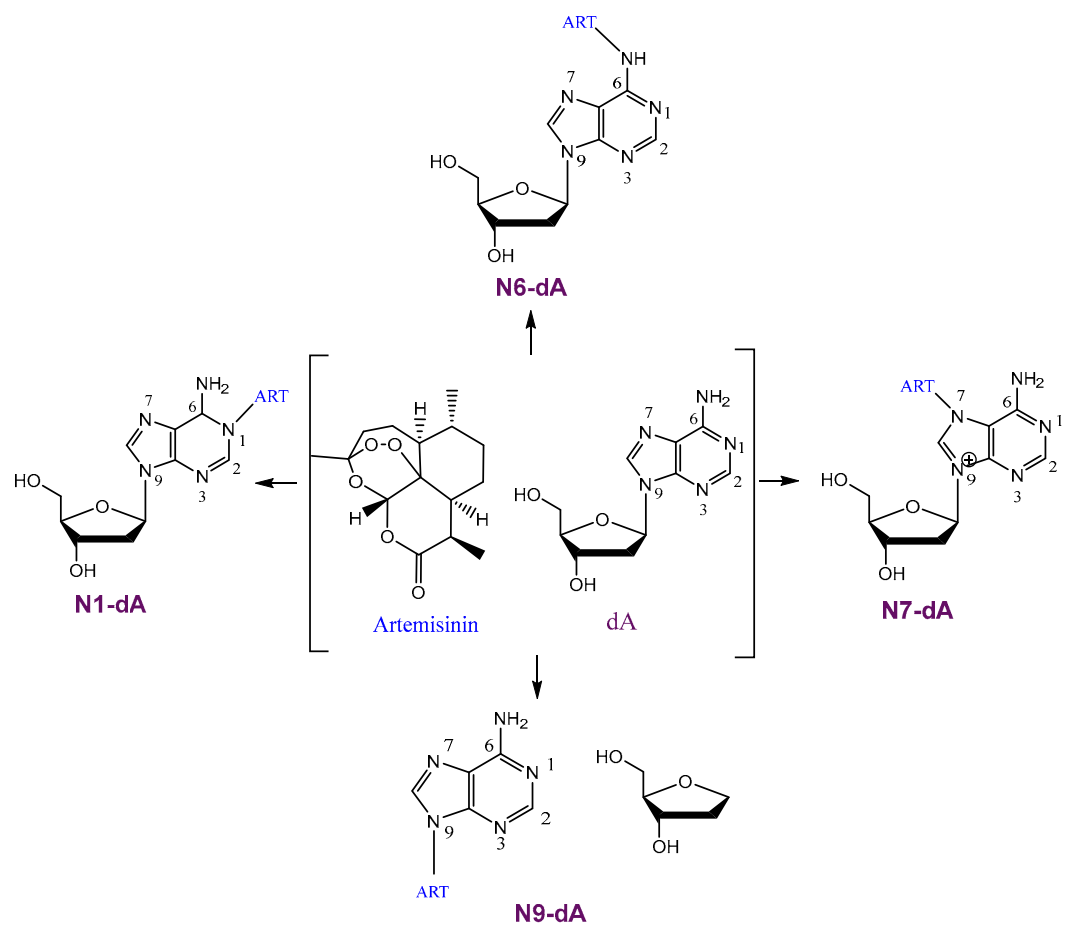

Figure 3. Possible adducts of deoxyadenosine (dA) alkylation on the N1, N6, N7, and N9 positions by ART.

Introduction of Iron (II) in the reaction mixture drastically changed both the number of chromatographic peaks as well as the retention times (Figure 4). To clearly evaluate the role of $\mathrm{Fe}^{2+}$, new reaction mixtures were made involving ART with $\mathrm{Fe}^{2+}, 1.4 \times 10^{-2} \mathrm{M}$ and $2 \times 10^{-3} \mathrm{M}$, respectively. Figure 4 a shows the chromatograms of ART and $\mathrm{Fe}^{2+}$. ART by itself showed a peak at 2.0 min retention time. After introduction of $\mathrm{Fe}^{2+}$, new chromatographic peaks at $0.91,0.97,1.2,1.4,1.8,2.5,3.1$ and 3.6 min retention times were observed. From the mass spectra, the new product chromatographic peaks appearing between 0.91 and 3.6 min retention times are shown in Table 2. 

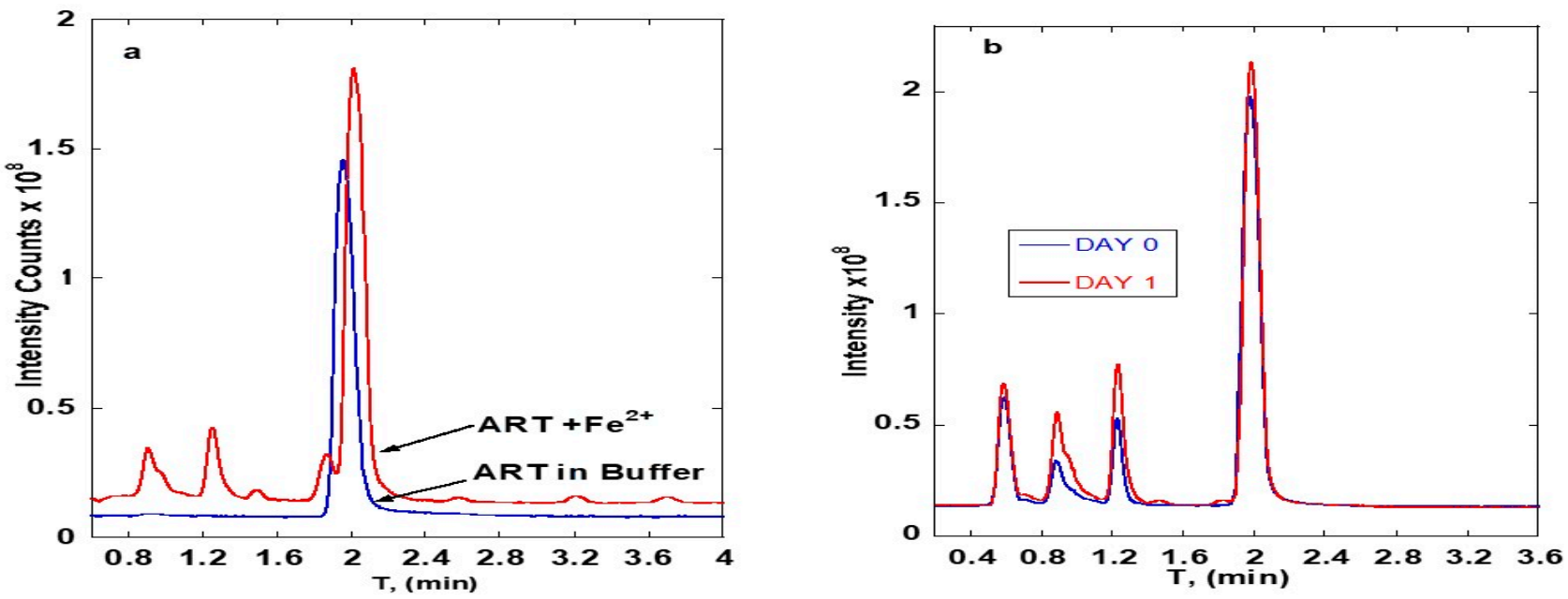

Figure 4. (a) TIC chromatograms for ART vs. ART-Fe ${ }^{2+}$ reaction obtained at room temperature. and at $37^{\circ} \mathrm{C}$. (b) $\mathrm{TIC}$ chromatograms of ART-deoxyadenosine- $\mathrm{Fe}^{2+}$ reaction obtained at room temperature and at $37^{\circ} \mathrm{C}$.

Table 2. Retention times and fragmentation patterns of artemisinin in the presence of $\mathrm{Fe}^{2+}$.

\begin{tabular}{ll}
\hline Retention Time & Main Fragments \\
\hline 0.91 & $265,283,305,314$, and 587 \\
\hline 0.97 & $203,209,237,265,277,283,305,314,321$ and 358 \\
\hline 1.2 & $223,300,305,314,328,356$ and 587 \\
\hline 1.4 & $203,209,251,297,332,337,346,360$, and 388 \\
\hline 1.8 & $209,251,265,315,332,337,346,353$ and 360 \\
\hline 2.5 & $203,209,224,237,251,265,279,297,337,346,358$, \\
\hline 3.1 & 360 and 399 \\
\hline 3.6 & $209,251,346,360$ and 374 \\
\hline
\end{tabular}

From these mass spectra, it appeared that ART's endo-peroxide bond opened up and reacted with itself to form the many ART derived products observed. Based on the short time this reaction took to happen, it appears to be occurring in a free radical fashion.

To establish whether this was the case, DNA bases were included in the mixture in sections that follow below (Figure 4b). Interaction of ART with deoxyadenosine in the presence of iron was monitored by observing chromatograms obtained from samples of ART, deoxyadenosine and $\mathrm{Fe}^{2+}$ mixtures and after incubation at room temperature and at $37{ }^{\circ} \mathrm{C}$. The sample mixtures were first analyzed immediately after mixing and then again each day for three days. On the first day, several small chromatogram peaks were obtained at about retention times $0.6,0.8,1.2$ and $2.0 \mathrm{~min}$ (Figure $4 \mathrm{~b}$ ). The chromatographic peaks at retention times 0.6 and 2.0 min were for deoxyadenosine and ART, respectively. Chromatographic peaks at retention time 0.8 and 1.2 were product reaction peaks formed from deoxyadenosine and ART at room temperature. On incubating the mixture at $37^{\circ} \mathrm{C}$, three new reaction peaks appeared at about $0.9,1.4$ and $1.8 \mathrm{~min}$, with mass spectra quite different from the previous results without $\mathrm{Fe}^{2+}$ ions. These new chromatographic reaction product peaks grew with time of incubation at $37^{\circ} \mathrm{C}$. Further analysis of these reaction products was carried out using mass spectra; spectra of the reaction products corresponding to Figure $4 \mathrm{~b}$ are shown in Figure S2. Presence of deoxyadenosine was indicated by presence of deoxyadenosine molecular ion $[\mathrm{M}+\mathrm{H}]^{+}$, similar to the previous result without $\mathrm{Fe}^{2+}$. Other ions include $[\mathrm{M}+\mathrm{Na}]^{+},[\mathrm{M}+\mathrm{K}]^{+}$, and $[2 \mathrm{M}+\mathrm{Na}]^{+}$, corresponding to $\mathrm{m} / \mathrm{z}$ of 274,290 and 525, respectively. On the other hand, ART, with a molecular weight of 282 showed 
molecular ions $[\mathrm{M}+\mathrm{H}]^{+}$, at $m / z 283$, in addition to other ions such as $[\mathrm{M}+\mathrm{Na}]^{+},[\mathrm{M}+\mathrm{K}]^{+}$, and $[2 \mathrm{M}+\mathrm{Na}]^{+}$, corresponding to $\mathrm{m} / z$ of 305,321 and 587 , respectively.

The retention times and mass fragmentation patterns of products appearing between retention times 0.8 and $1.8 \mathrm{~min}$ are given in Table 3.

Table 3. Retention times and fragmentation patterns of Deoxyadenosine reacted with artemisinin in the presence of $\mathrm{Fe}^{2+}$.

\begin{tabular}{ll}
\hline Retention Time (min) & Main Fragments $(\mathrm{m} / \mathrm{z})$ \\
\hline 0.8 & $252,283,305,337,367,587$, and 619 \\
\hline 0.9 & $203,209,237,252,277,283,293,305,411,531$, and 547 \\
\hline 1.2 & $223,255,279,305,314,321,356,443$ and 587 \\
\hline 1.4 & $\begin{array}{l}203,217,251,252,269,291,293,297,305,319,328,337,346, \\
\text { and } 370\end{array}$ \\
\hline 1.8 & $203,209,251,277,337,346,353$ and 360 \\
\hline
\end{tabular}

These masses consist of those from ART as well as those from adenosine. The fact that these masses are from different molecules than those observed when no iron was included points to a different mechanism of formation for these molecules.

Based on the products formed, it was hypothesized that there is a difference in the mechanism of the reaction between ART and deoxyadenosine when iron is present. In general, iron II in the presence of hydrogen peroxide is known to form Fenton's reagent [22]. We speculated that ART in the presence of iron II could also form a similar type of reaction. When the endoperoxide in ART interacts with iron, it forms free radicals [10]. Activated ART can react with the DNA base, forming adducts, and also reacts with itself, forming dimers. As observed from the chromatogram and mass spectra, the products mediated by free radical reactions are different from the products formed without the free radical route.

\subsection{ART-Deoxycytidine}

Chromatograms of the reaction of ART and deoxycytidine obtained at room temperature and at $37{ }^{\circ} \mathrm{C}$ are given in Figure 5a. At day 0 (at room temperature), three chromatogram peaks were obtained at about $0.5,0.6$ and $2.0 \mathrm{~min}$. The peaks at 0.5 and 2.0 min belonged to deoxycytidine and ART, respectively, while the other at $0.6 \mathrm{~min}$ was the reaction product of ART and deoxycytidine at room temperature. On subjecting the mixture solution to $37^{\circ} \mathrm{C}$, five new reaction peaks appeared at about 1.2, 1.4, 1.8, 3.1 and $3.6 \mathrm{~min}$. The reaction product peaks grew with time of incubation at $37^{\circ} \mathrm{C}$ while the parent peaks reduced. The initial reactant signature peaks decreased by about 6 to $60 \%$, while the new product peaks grew by about 100\% during the time of incubation. The identity of the reaction products was confirmed by observing the mass spectra of these molecules. Figure S3 shows the mass spectra of chromatographic peaks shown in Figure 5. Deoxycytidine molecular ion $[\mathrm{M}+\mathrm{H}]^{+}$was observed at $m / z$ 228. Other ions including $[\mathrm{M}+\mathrm{Na}]^{+}$, $[2 \mathrm{M}+\mathrm{H}]^{+}$, and $[2 \mathrm{M}+\mathrm{Na}]^{+}$, corresponding to $\mathrm{m} / z$ of 250,455 and 477 , respectively. On the other hand ART, with a molecular weight of 282 , showed molecular ions $[\mathrm{M}+\mathrm{H}]+$ at $m / z$ 283 , in addition to other ions such as $[\mathrm{M}+\mathrm{Na}]^{+},[\mathrm{M}+\mathrm{K}]^{+},[2 \mathrm{M}+\mathrm{Na}]^{+}$, corresponding to $\mathrm{m} / \mathrm{z}$ of 305,321 and 587, respectively. The retention times and mass fragmentation patterns of products appearing at retention times between 1.2 and $3.6 \mathrm{~min}$ are given in Table 4 . 

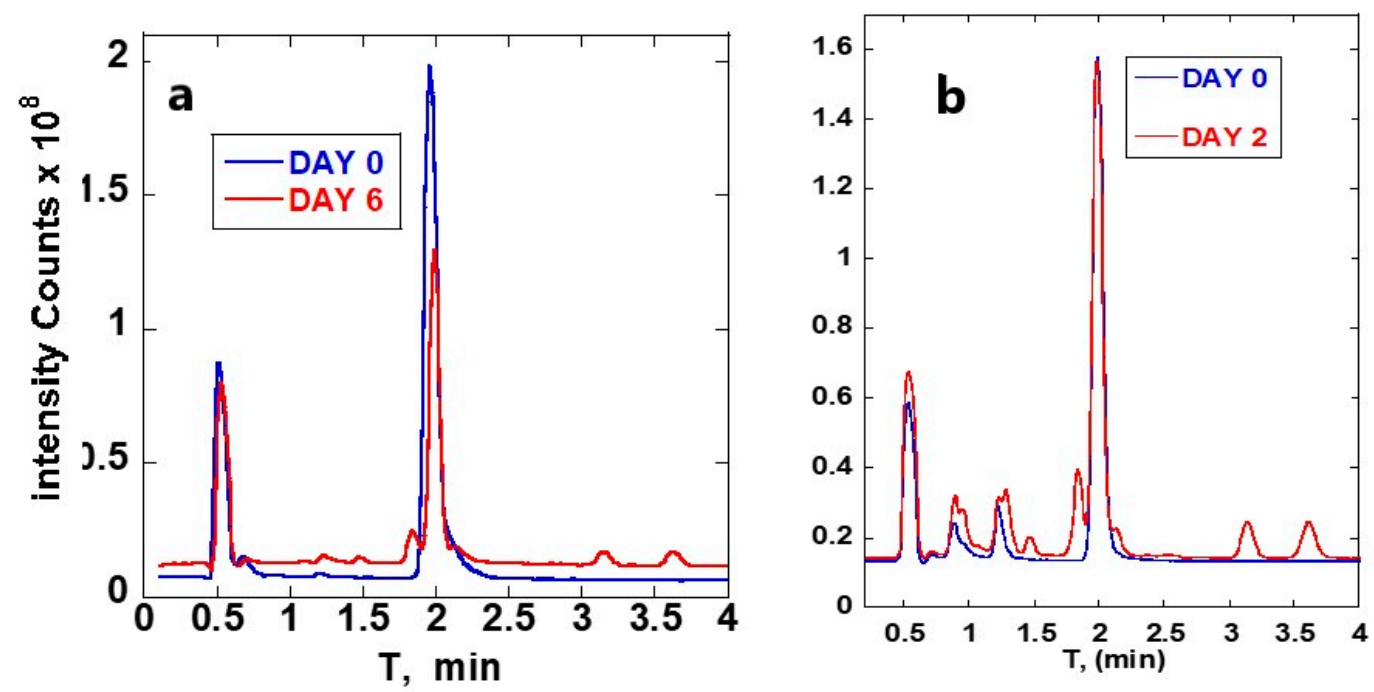

Figure 5. (a) TIC chromatograms of the ART and deoxycytidine reaction obtained at room temperature and at $37^{\circ} \mathrm{C}$. (b) TIC chromatograms of the ART-deoxycytidine- $\mathrm{Fe}^{2+}$ reaction obtained at room temperature and at $37^{\circ} \mathrm{C}$.

Table 4. Retention times and main fragmentation patterns of Deoxycytidine reacted with artemisinin.

\begin{tabular}{ll}
\hline Retention Time & Main Fragments $(\mathrm{m} / \mathbf{z})$ \\
\hline 1.2 & $203,209,284,291,305,323,332$ and 337 \\
\hline 1.4 & $203,224,245,251,284,291,337,346,360$, and 388 \\
\hline 1.8 & $209,251,277,337$ and 346 \\
\hline 3.1 & $209,251,277,284,307,346,351,360$ and 374 \\
\hline 3.6 & $209,251,277,297,307,351,360$ and 374 \\
\hline
\end{tabular}

Alkylation most likely occurs in the reaction between the drug and the DNA base, which leads to the formation of ART-deoxycytidine adducts. In principle, alkylation of 2'deoxycytidine can occur at nitrogen atoms, N3 and N4, and at the oxygen atom. Alkylation at multiple location in deoxycytidine could be one of the key reasons for encountering different molecules representing the same masses in the mass spectra. These adducts undergo mass fragmentation and are represented by the reaction peaks indicating presence of both deoxycytidine and ART mass fragmented ions. It is possible that the mechanism of deoxycytidine $(\mathrm{dC})$ alkylation at $\mathrm{N} 3, \mathrm{~N} 4$, and $O^{2}$ positions by ART occurred under temperature control. Figure S4 shows deoxycytidine alkylation on the N3, N4, and $O^{2}$ positions by Artemisinin (ART). This kind of alkylation mechanism on deoxycytidine was previously reported in $[23,24]$. Studies show that alkylation at the N3 position is favored in reaction in water, and can be reversible and less stable compared to $\mathrm{N} 4$, whereas under thermodynamic control $\mathrm{N} 4$ alkylation will be more likely to take place. Alkylation at the $\mathrm{O}^{2}$ position was proposed even though it is less likely [23].

Free interaction of ART with deoxycytidine in the presence of iron was monitored by obtaining chromatograms of mixtures of theses samples after incubation at room temperature and at $37^{\circ} \mathrm{C}$. The chromatograms obtained are given in Figure $5 \mathrm{~b}$. The sample mixtures were first analysed immediately after mixing, then analysed again each day for four days. On the first day, several chromatogram peaks were obtained at about retention times $0.5,0.8,1.2$ and $2.0 \mathrm{~min}$. The chromatographic peaks at retention times 0.5 and $2.0 \mathrm{~min}$ were for deoxycytidine and ART, respectively. The chromatographic peak at retention time at 1.2 min was from ART with $\mathrm{Fe}^{2+}$. On incubating the mixture at $37^{\circ} \mathrm{C}$, seven new reaction peaks appeared at about $0.9,1.3,1.4,1.8,2.1,3.1$ and $3.6 \mathrm{~min}$. These new chromatographic reaction product peaks grew with time of incubation at $37^{\circ} \mathrm{C}$. Further analysis of these reaction products was carried out using mass spectra. 
The mass spectra of the chromatographic peaks shown in Figure $5 b$ are given in the supplemental information (Figure S5). Deoxycytidine molecular ion $[\mathrm{M}+\mathrm{H}]^{+}$was observed at $m / z$ 228. Other ions included $[\mathrm{M}+\mathrm{Na}]^{+},[2 \mathrm{M}+\mathrm{H}]^{+},[2 \mathrm{M}+\mathrm{Na}]^{+}$and $[2 \mathrm{M}+\mathrm{K}]^{+}$, corresponding to $\mathrm{m} / \mathrm{z}$ of $250,455,477$ and 493 , respectively. On the other hand ART, with a molecular weight of 282, showed molecular ions $[\mathrm{M}+\mathrm{H}]^{+}$, at $m / z 283$, in addition to other ions such as $[\mathrm{M}+\mathrm{Na}]^{+},[\mathrm{M}+\mathrm{K}]^{+},[2 \mathrm{M}+\mathrm{Na}]^{+}$, corresponding to $m / z$ of 305,321 and 587 , respectively. The $m / z$ for the reaction products observed at $0.8,0.9,1.2,1.3,1.4,1.8,2.1,3.1$ and 3.6 min are given here. The new product chromatographic peaks and fragmentation patterns appearing between 0.8 and 3.6 min are shown in Table 5.

Table 5. Fragmentation patterns of the products of deoxycytidine reacted with artemisinin in the presence of $\mathrm{Fe}^{2+}$.

\begin{tabular}{ll}
\hline Retention Time & Main Fragments $(\mathrm{m} / \mathrm{z})$ \\
\hline 0.8 & $283,305,314,337,587$, and 619 \\
\hline 0.9 & $209,237,277,283,293,305$, and 531 \\
\hline 1.2 & $223,305,314,321,356,587$ and 605 \\
\hline 1.3 & $251,291,300$ and 307 \\
\hline 1.4 & $251,291,297,307,319,337,346,353,360,374$ \\
\hline 1.8 & and 388 \\
\hline 2.1 & $251,277,297,337,346$, and 353 \\
\hline 3.1 & $209,237,265,283,305,337,346,353$ and 356 \\
\hline 3.6 & $251,346,351,360,367$ and 374 \\
\hline
\end{tabular}

\section{Discussion}

Based on the products formed, it was clear there was a difference in the mechanism of the reaction between ART and the DNA bases when iron was present. In general, iron II in the presence of hydrogen peroxide is known to form Fenton's reagent [22]. We speculated that ART in the presence of iron II could also form a similar type of reaction. When the endoperoxide in ART interacts with iron, it forms free radicals [10]. Activated ART reacts with the DNA base, forming adducts, and also reacts with other molecules, including itself, to form dimers. As observed from the chromatograms and mass spectra, the products mediated by free radical reactions are different from the products formed without free radical route. The two reactions most likely proceed side by side when ART is administered for the treatment of various diseases. A study of the molecular transformation of ART moiety in the presence of a host of biological molecules would definitely open up new understanding of molecular pathways involving ART and its derivatives, and hence help to tailor new therapies. ART is one the few exceptions that work non-stereo specifically, enabling easy laboratory synthesis of active forms of the drug.

\section{Conclusions}

Understanding the mechanism of reaction involving ART and DNA can help unravel potential reactions when these drugs are administered. In this work, we have explored the interactions of ART with DNA bases, ART with $\mathrm{Fe}^{2+}$, and ART with both DNA and $\mathrm{Fe}^{2+}$. Reaction of ART with DNA bases was found to give rise to new adducts, as observed from new chromatographic peaks showing both the DNA base and ART signatures. These reactions were only observed when the mixture was incubated at $37^{\circ} \mathrm{C}$. Incubation of ART with $\mathrm{Fe}^{2+}$ caused the formation of several new molecules, indicating breakdown of the peroxide bond. Formation of new reaction products was not time dependent, as observed from chromatograms typical of free radical reactions. Study of ART and its derivatives with biological molecules is key to understanding the drug's activity in vivo. 
Supplementary Materials: The following are available online at https: / www.mdpi.com/article/ 10.3390 / separations8090161/s1, Figure S1. Mass spectrum of artemisinin-deoxyadenosine reaction products at $0.7 \mathrm{~min}(\mathrm{~A}), 0.8 \mathrm{~min}(\mathrm{~B}), 0.9 \mathrm{~min}(\mathrm{C}), 1.1 \mathrm{~min}(\mathrm{D})$ and $1.2 \mathrm{~min}(\mathrm{E})$. Figure S2. Mass spectrum of artemisinin-deoxyadenosine- $\mathrm{Fe}^{2+}$ at $0.8 \mathrm{~min}(\mathrm{~A}), 0.9 \mathrm{~min}(\mathrm{~B}), 1.2 \mathrm{~min}(\mathrm{C}), 1.4(\mathrm{D})$, and 1.8 (E). Figure S3. Mass spectrum of artemisinin-deoxycytidine reaction products at $1.2 \mathrm{~min}(\mathrm{~A})$, $1.4 \mathrm{~min}(\mathrm{~B}), 1.8 \mathrm{~min}(\mathrm{C}), 3.1 \mathrm{~min}(\mathrm{D})$, and $3.6 \mathrm{~min}(\mathrm{E})$. Figure S4. Possible mechanism of deoxycytidine (dC) alkylation on the N3, N4, and $2 \mathrm{O}$ positions by Artemisinin (ART) under temperature control. Figure S5: Mass spectrum of artemisinin-deoxycytidine-Fe ${ }^{2+}$ at $0.8 \mathrm{~min}(\mathrm{~A}), 0.9 \mathrm{~min}(\mathrm{~B}), 1.2 \mathrm{~min}(\mathrm{C})$, $1.3 \mathrm{~min}(\mathrm{D}), 1.4(\mathrm{E}), 1.8(\mathrm{~F}), 2.1(\mathrm{G}), 3.1(\mathrm{H})$ and $3.6(\mathrm{I})$. Table S1. Identification of mass fragments of artemisinin-deoxyadenosine reaction products. Table S2. Identification of mass fragments of artemisinin-deoxyadenosine- $\mathrm{Fe}^{2+}$ reaction products.

Author Contributions: Conceptualization, methodology, validation was done by A.M.; Formal analysis, investigation, data curation, writing-original draft preparation, was done by K.O.; Review and editing, visualization, supervision, and project administration was done by A.M. All authors have read and agreed to the published version of the manuscript.

Funding: This research received no external funding.

Institutional Review Board Statement: Not applicable.

Informed Consent Statement: Not applicable.

Data Availability Statement: Data are available upon request to the corresponding author.

Acknowledgments: The authors would like to acknowledge Rowan University for the Research Fellowship provided as well departmental facilities that enabled this work.

Conflicts of Interest: The authors declare no conflict of interest.

\section{References}

1. Ivanescu, B.; Miron, A.; Corciova, A. Sesquiterpene Lactones fromArtemisiaGenus: Biological Activities and Methods of Analysis. J. Anal. Methods Chem. 2015, 2015, 247685. [CrossRef]

2. Van Geldre, E.; Vergauwe, A.; Eeckhout, E.V.D. State of the art of the production of the antimalarial compound artemisinin in plants. Plant Mol. Biol. 1997, 33, 199-209. [CrossRef]

3. Rudrapal, M.; Chetia, D. Endoperoxide antimalarials: Development, structural diversity and pharmacodynamic aspects with reference to 1,2,4-trioxane-based structural scaffold. Drug Des. Dev. Ther. 2016, 10, 3575-3590. [CrossRef]

4. Woodrow, C.J.; Haynes, R.K.; Krishna, S. Artemisinins. Postgrad. Med. J. 2005, 81, 71-78. [CrossRef] [PubMed]

5. Meshnick, S.R.; Taylor, T.E.; Kamchonwongpaisan, S. Artemisinin and the antimalarial endoperoxides: From herbal remedy to targeted chemotherapy. Microbiol. Rev. 1996, 60, 301-315. [CrossRef]

6. Chen, X.; He, L.-Y.; Lai, S.; He, Y. Dihydroartemisinin inhibits the migration of esophageal cancer cells by inducing autophagy. Oncol. Lett. 2020, 20, 94. [CrossRef] [PubMed]

7. Augustin, Y.; Staines, H.M.; Krishna, S. Artemisinins as a novel anti-cancer therapy: Targeting a global cancer pandemic through drug repurposing. Pharmacol. Ther. 2020, 216, 107706. [CrossRef]

8. Konstat-Korzenny, E.; Ascencio-Aragon, J.A.; Niezen-Lugo, S.; Vazquez-Lopez, R. Artemisinin and its synthetic derivatives as a possible therapy for cancer. Med. Sci. 2018, 6, 19. [CrossRef] [PubMed]

9. Wang, J.; Huang, L.; Li, J.; Fan, Q.; Long, Y.; Li, Y.; Zhou, B. Artemisinin directly targets malarial mitochondria through its specific mitochondrial activation. PLoS ONE 2010, 5, e9582. [CrossRef]

10. Waseem, Y.; Hasan, A.C.; Ahmed, F. Artemisinin: A promising adjunct for cancer therapy. Cureus 2018, 10, e3628. [CrossRef]

11. Accardo, A.; Laurent, S.A.L.; Mazarguil, H.; Meyer, M.; Robert, A.; Meunier, B. Interaction of iron(II)-heme and artemisinin with a peptide mimic of Plasmodium falciparum HRP-II. J. Inorg. Biochem. 2007, 101, 1739-1747. [CrossRef] [PubMed]

12. Guo, S.; Yao, X.; Jiang, Q.; Wang, K.; Zhang, Y.; Peng, H.; Tang, J.; Yang, W. Dihydroartemisinin-loaded magnetic nanoparticles for enhanced chemodynamic therapy. Front. Pharmacol. 2020, 11, 226. [CrossRef] [PubMed]

13. Gao, Z.; Li, Y.-J.; You, C.; Sun, K.; An, P.; Sun, C.; Wang, M.-X.; Zhu, X.; Sun, B.-W. Iron oxide nanocarrier-mediated combination therapy of cisplatin and artemisinin for combating drug resistance through highly increased toxic reactive oxygen species generation. ACS Appl. Bio Mater. 2018, 1, 270-280. [CrossRef]

14. Sen, R.; Ganguly, S.; Saha, P.; Chatterjee, M. Efficacy of artemisinin in experimental visceral leishmaniasis. Int. J. Antimicrob. Agents 2010, 36, 43-49. [CrossRef] [PubMed]

15. Patel, Y.; Mistry, N.; Mehra, S. Repurposing artemisinin as an anti-mycobacterial agent in synergy with rifampicin. Tuberculosis 2019, 115, 146-153. [CrossRef] [PubMed] 
16. Ortalli, M.; Varani, S.; Cimato, G.; Veronesi, R.; Quintavalla, A.; Lombardo, M.; Monari, M.; Trombini, C. Evaluation of the pharmacophoric role of the $\mathrm{O}-\mathrm{O}$ bond in synthetic antileishmanial compounds: Comparison between 1,2-dioxanes and tetrahydropyrans. J. Med. Chem. 2020, 63, 13140-13158. [CrossRef]

17. Geroldinger, G.; Tonner, M.; Quirgst, J.; Walter, M.; De Sarkar, S.; Machín, L.; Monzote, L.; Stolze, K.; Duvigneau, J.C.; Staniek, K.; et al. Activation of artemisinin and heme degradation in Leishmania tarentolae pro-mastigotes: A possible link. Biochem. Pharmacol. 2020, 173, 113737. [CrossRef]

18. Chen, G.-Q.; Benthani, F.A.; Wu, J.; Liang, D.; Bian, Z.-X.; Jiang, X. Artemisinin compounds sensitize cancer cells to ferroptosis by regulating iron homeostasis. Cell Death Differ. 2020, 27, 242-254. [CrossRef]

19. Alotaibi, S.H.; Momen, A.A. Antinticancer drugs' deoxyribonucleic acid (DNA) interactions. In Biophysical Chemistry—Advanced Applications; Khalid, M.A.A., Ed.; InTech Open: London, UK, 2019. [CrossRef]

20. Vandercruyssen, K.; D'Hondt, M.; Vergote, V.; Jansen, H.; Burvenich, C.; De Spiegeleer, B. LC-UV/MS quality analytics of pediatric artemether formulations. J. Pharm. Anal. 2013, 4, 37-52. [CrossRef]

21. Naumczuk, B.; Bocian, W.; Sitkowski, J.; Kawęcki, R.; Kozerski, L. Solvent-dependent regioselectivity of 2'-deoxyadenosine alkylation by 9-aminomethyl derivatives of SN38. New J. Chem. 2019, 43, 18975-18978. [CrossRef]

22. Liu, X. Progress in the mechanism and kinetics of Fenton reaction. MOJ Ecol. Environ. Sci. 2018, 3, 60. [CrossRef]

23. Naumczuk, B.; Kawęcki, R.; Bocian, W.; Bednarek, E.; Sitkowski, J.; Kozerski, L. Regioselective alkylation reaction of the 2'-deoxyctidine with 9-aminomethyl derivatives of SN38. J. Mol. Struct. 2018, 1176, 298-302. [CrossRef]

24. Koskinen, M.; Calebiro, D.; Hemminki, K. Styrene oxide-induced 2'-deoxycytidine adducts: Implications for the mutagenicity of styrene oxide. Chem. Biol. Interact. 2000, 126, 201-213. [CrossRef] 